\title{
STRUCTURAL REASSIGNMENT OF EPIERYTHRATIDINE, AN ALKALOID FROM Erythrina fusca, BASED ON NMR STUDIES AND COMPUTATIONAL METHODS
}

\author{
OLIMPO GARCÍA-BELTRÁN, ${ }^{a, c *}$ JORGE SOTO-DELGADO, ${ }^{a}$ PATRICIO ITURRIAGA-VÁSQUEZ,,${ }^{a, b}$ \\ CARLOS ARECHE, ${ }^{a}$ AND BRUCE K. CASSELS $S^{a, b_{*}}$
}

\author{
a Department of Chemistry, Faculty of Sciences, University of Chile, Santiago, Chile. \\ ${ }^{b}$ Institute for Cell Dynamics and Biotechnology, University of Chile, Santiago, Chile. \\ ${ }^{c}$ Departamento de Ciencias Químicas, Facultad de Ciencias Exactas, \\ Universidad Andres Bello, Avenida República 275, Piso 3, Santiago, Chile
}

(Received: May 9, 2012 - Accepted: July 5, 2012)

\begin{abstract}
The diene Erythrina alkaloids erysotrine (1), erysodine (2), erythraline (3), erytharbine (4), and erysotrine $N$-oxide (5), plus the hydroxylated dihydro derivative of 1, epierythratidine (6) were isolated from seeds of Erythrina fusca Lour., and their ${ }^{1} \mathrm{H}$ and ${ }^{13} \mathrm{C}$ NMR spectra were completely assigned using $2 \mathrm{D}$ experiments (H-H COSY, HMQC, HMBC and H-H NOESY). Our assignments for 1-5 agree well with the literature, but the present work shows that the published interpretation of the spectra of $\mathbf{6}$ must be revised. A combined study based on NMR data and quantum-mechanical calculations using DFT/GIAO indicate that $\mathbf{6}$ is the correct structure of epierythratidine.
\end{abstract}

Keywords: Erythrina alkaloids; Erythrina fusca; epierythratidine; ${ }^{1} \mathrm{H}$ NMR; ${ }^{13} \mathrm{C}$ NMR; 2D NMR; GIAO/DFT methods

\section{INTRODUCTION}

The Erythrina alkaloids constitute a medium-sized group of natural products sharing a 1,2,3,4,5,6,8,9-octahydroindolo[7a,1a]isoquinoline skeleton that are limited to the plant genera Erythrina (Fabaceae), Cocculus, Hyperbaena and Pachygone (Menispermaceae). The earliest structural studies on these compounds antedated the existence of practical NMR spectrometers and, indeed, the discovery of nuclear magnetic resonance. However, in the 1960 's ${ }^{1} \mathrm{H}$ NMR began to be used routinely in the structure elucidation of natural products, and in 1983 a seminal paper was published in which the ${ }^{13} \mathrm{C}$ NMR spectra of 20 Erythrina alkaloids were described and interpreted. ${ }^{1}$ A 1991 review collected the spectroscopic data of all the members of this family known at that date, ${ }^{2}$ including the ${ }^{1} \mathrm{H}$ NMR assignments of 66 of them and the ${ }^{13} \mathrm{C}$ NMR assignments of 27 compounds (which include the $20{ }^{13} \mathrm{C}$ NMR interpretations published in 1983). More recent work, based on ${ }^{1} \mathrm{H}-{ }^{1} \mathrm{H}$ COSY, NOESY and ${ }^{1} \mathrm{H}-{ }^{13} \mathrm{C} 2 \mathrm{D}$ spectra (e.g. HMQC and HMBC) ${ }^{3-9}$ shows broad agreement with the generally accepted ${ }^{13} \mathrm{C}$ NMR patterns of the more extensively studied 1,2,7,8-didehydro 'dienoid' series.

Theoretical methods have been used to calculate the ${ }^{1} \mathrm{H}$ and ${ }^{13} \mathrm{C}$ chemical shifts in several natural products. ${ }^{10-12}$ These methods have been very important, together with total synthesis, ${ }^{13}$ to determine the structures of unusual natural substances,,${ }^{14,15}$ and differentiate diastereoisomers, ${ }^{16}$ through calculations of proton-proton and proton-carbon $J$ coupling constants as a tool for the assignment of the relative configurations of chiral organic compounds, an approach that agrees very well with the experimental data. ${ }^{17-18}$

Moreover, extensive spectroscopic analyses and quantum mechanical (QM) methods have been used for the reassignment of some structures ${ }^{19}$ and can be very helpful to confirm both rigid and flexible molecular scaffolds. ${ }^{20,21}$ On the other hand, this methodology has been used to derive stereostructures by comparing the experimental NMR spectroscopic data with the corresponding results of calculations for all the possible stereoisomers. ${ }^{22-24}$

In this work we report the isolation of erysotrine (1), erysodine (2), erythraline (3), erytharbine (4), erysotrine $N$-oxide (5) and epierythratidine (6) from the seeds of Erythrina fusca Lour. The systematic numbering of the fundamental structure of these alkaloids and the commonly used 'erythrinan' numbering are shown in Figure 1. An additional result of this paper is the reassignment of the structure of epierythratidine which had been reported on the sole basis of its one-dimensional ${ }^{1} \mathrm{H}$ and ${ }^{13} \mathrm{C}$ NMR spectra and comparison of its spectroscopic data with those of analogous Erythrina alkaloids. In order to complete this limited spectroscopic information, we performed a full assignment of the ${ }^{1} \mathrm{H}$ and ${ }^{13} \mathrm{C}$ NMR spectra of this compound using one- and two-dimensional NMR experiments. This study suggested that the correct structure of epierythratidine is $\mathbf{6}$ instead of the originally proposed diastereomeric structure. We then used the DFT/GIAO method to find further support for our assignment through the analysis of both stereoisomers at the $\mathrm{C} 2$ position. In this case comparison of the experimental and calculated ${ }^{13} \mathrm{C}$ NMR chemical shifts proved once more to be a valuable tool to aid in the elucidation of the correct structure of a natural product. a)

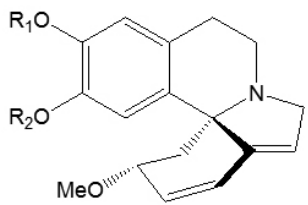

Erysotrine (1) $R_{1}=R_{2}=M e$ Erysodine (2) $\mathrm{R}_{1}=\mathrm{Me} ; \mathrm{R}_{2}=\mathrm{H}$

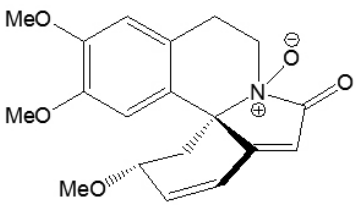

Erysotrine $\mathrm{N}$-oxide (5) Erythraline (3) $\mathrm{R}_{1}{ }^{+} \mathrm{R}_{2}=-\mathrm{CH}_{2}{ }^{-}$<smiles>CCN1[C@H]2C=CC3=CC(=O)c4cc(OC)c(OC)cc4[C@@]31CC2</smiles>

Erytharbine (4)

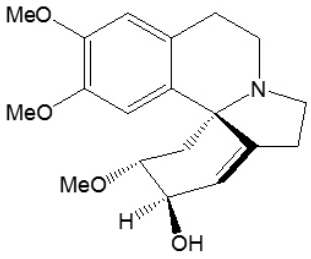

Epierythratidine (6) b)

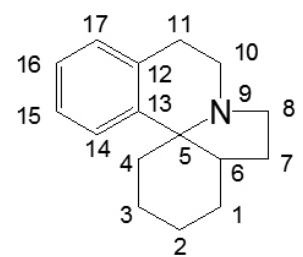

Figure 1. (a) Structures of the alkaloids isolated from seed the Erythrina fusca Lour.

(b) Numbering schemes of the Erythrina alkaloid skeleton. 


\section{RESULTS AND DISCUSSION}

A decade ago Calle et al. reported the isolation of epierythratidine (6) and 8-oxoerysodine from the bark and flowers of E. fusca ${ }^{25}$ and previously several other alkaloids had been observed as constituents of the seeds, but without isolating them and only on the basis of a GC/MS study. ${ }^{26}$ The isolation of erysotrine (1), erysodine (2), erythraline (3), erytharbine (4), erysotrine $\mathrm{N}$-oxide (5) and epierythratidine (6) from the seeds of this species was now carried out following a general protocol for alkaloids. The only noteworthy feature is the relatively high yield (for the usually scanty Erythrina alkaloids) and facile crystallization of $\mathbf{6}$. All six compounds were identified by comparison of their NMR data with published values which only showed some discrepancies, discussed below, in the case of $\mathbf{6}$. A combination of one- and two-dimensional NMR $\left({ }^{1} \mathrm{H}\right.$ and $\left.{ }^{13} \mathrm{C}\right)$ methods led to conclusions in complete agreement with the literature assignments for $\mathbf{1 - 5},{ }^{2}$ which had generally been based on one-dimensional experiments. In the case of epierythratidine (6), however, our results and the published assignments, ${ }^{1,26}$ also based on onedimensional experiments, were at variance. Epierythratidine has a somewhat unusual structure differing from most Erythrina alkaloids in having a partially hydrogenated diene system and bearing a hydroxyl group at C-2. Considering this rare hydroxyl substitution on the spiro cyclohexene ring next to a methoxyl group which could lead to some confusion, we confirmed our assignment with further experiments summarized in Table 1.

Table 1. ${ }^{1} \mathrm{H}$ and ${ }^{13} \mathrm{C}$ NMR assignments of epierythratidine (6) with ${ }^{1} \mathrm{H}-{ }^{1} \mathrm{H}$ COSY, HMQC, HMBC, and NOESY correlations.

\begin{tabular}{|c|c|c|c|c|c|c|c|c|}
\hline C No. & ${ }_{1}^{13} \mathrm{C} \mathrm{NMR}^{*}$ & $\begin{array}{c}{ }^{13} \mathrm{C} \\
\mathrm{NMR}^{* 10}\end{array}$ & ${ }^{13} \mathrm{C}$ NMR & ${ }^{1} \mathrm{H} \mathrm{NMR} \dagger$ & $\begin{array}{l}{ }^{1} \mathrm{H}-{ }^{1} \mathrm{H} \\
\mathrm{COSY}\end{array}$ & HMQC & HMBC & NOESY \\
\hline 1 & 121.3 & 121.3 & 125.3 & $5.8(\mathrm{sb}, 1 \mathrm{H})$ & $\mathrm{H}-2,7$ & 125.3 & $25.60,66.99,80.17$ & $\mathrm{H}-2, \mathrm{H}-7$ (one) \\
\hline 2 & 81.0 & 81.5 & 71.36 & $4.2(\mathrm{~m}, 1 \mathrm{H})$ & $\mathrm{H}-3$ & 71.36 & $80.17,139.3$ & \\
\hline 3 & 72.7 & 72.3 & 80.17 & $3.6(12.0,4.3,1 \mathrm{H})$ & $\mathrm{H}-4$ & 80.17 & $71.36,139.3$ & $\mathrm{H}-3, \mathrm{H}-4$ (one) \\
\hline 4 & 40.1 & 40.1 & 37.76 & $\begin{array}{c}1.75(12.0, \mathrm{t}, 1 \mathrm{H}) \\
2.4(12.0,4.0 \mathrm{dd}, 1 \mathrm{H})\end{array}$ & & 37.76 & $\begin{array}{c}66.99,71.36,80.17,124.4 \\
139.3\end{array}$ & \\
\hline 6 & 143.8 & 144.2 & 139.3 & & & & & \\
\hline 7 & 26.7 & 26.3 & 25.60 & $\begin{array}{l}2.36(\mathrm{~m}, 1 \mathrm{H}) \\
2.54(\mathrm{~m}, 1 \mathrm{H})\end{array}$ & & 25.60 & $37.76,125.8$ & \\
\hline 8 & 39.3 & 39.3 & 46.74 & $\begin{array}{l}3.07(\mathrm{~m}, 1 \mathrm{H}) \\
3.26(\mathrm{~m}, 1 \mathrm{H})\end{array}$ & $\mathrm{H}-7$ & 46.74 & $20.85,66.99$ & H-7 (both) \\
\hline 10 & 46.3 & 46.3 & 40.09 & $\begin{array}{c}3.36(\mathrm{~m}, 1 \mathrm{H}) \\
3.67(7.0,2.8 \mathrm{dd}, 1 \mathrm{H})\end{array}$ & $\mathrm{H}-11$ & 40.09 & $20.85,46.74,123.8,139.3$ & $\begin{array}{l}\mathrm{H}-11 \text { (both), } \mathrm{H}-8 \\
\text { (both) }\end{array}$ \\
\hline 13 & 127.8 & 128 & 124.4 & & & & & \\
\hline 14 & 111.1 & 111.1 & 110.8 & $6.80(\mathrm{~s}, 1 \mathrm{H})$ & & 106.2 & $66.99,110.8,149.4$ & $\mathrm{H}-3$ \\
\hline 15 & 147.9 & 147.9 & 147.4 & & & & & \\
\hline 16 & 146.6 & 146.5 & 149.4 & & & & & \\
\hline 17 & 111.8 & 111.8 & 112.4 & $6.78(\mathrm{~s}, 1 \mathrm{H})$ & $\mathrm{H}-11$ & 112.4 & $20.85,112.4,123.8,149.4$ & $\begin{array}{c}\mathrm{H}-3^{\prime}, \mathrm{H}-11 \text { (both), } \\
\mathrm{H}-3^{\prime}\end{array}$ \\
\hline $1^{\prime}$ & $?$ & 57.1 & 56.45 & $3.30(\mathrm{~s}, 3 \mathrm{H})$ & & 56.45 & 80.17 & \\
\hline $2^{\prime}$ & 56.0 & 55.9 & 55.51 & $3.76(\mathrm{~s}, 3 \mathrm{H})$ & & 55.51 & $147.4,110.8$ & \\
\hline $3^{\prime}$ & 55.7 & 55.8 & 55.14 & $3.78(\mathrm{~s}, 3 \mathrm{H})$ & & 55.14 & $149.4,112.4$ & \\
\hline
\end{tabular}

*Values in these columns were taken from the literature. ${ }^{1,19}$

$\dagger \mathrm{d}(J$ values, in $\mathrm{Hz}$, in parentheses).

Epierythratidine (6) was obtained as an off-white crystalline solid. Its ${ }^{1} \mathrm{H}$ NMR spectrum shows signals at $\delta 1.75(\mathrm{t}, 1 \mathrm{H}, J=12.0 \mathrm{~Hz})$ and $2.42(\mathrm{dd}, 1 \mathrm{H}, J=$ $12.0,4.0 \mathrm{~Hz}$ ) suggesting the presence of a methylene group with diastereotopic protons. A heteroatom-bonded methine produces a signal at $\delta 3.61(\mathrm{ddd}, 1 \mathrm{H}, J$ $=12.0,7.0,4.3 \mathrm{~Hz}$ ) and, judging from its coupling constants, it seemed likely to be attached to the former methylene. Another proton gives rise to a signal at $\delta 4.24(\mathrm{~m}, 1 \mathrm{H})$ and also appears to be bonded to a heteroatom and, although it does not seem to be coupled to the previously mentioned protons, a ${ }^{1} \mathrm{H}-{ }^{-1} \mathrm{H}$ COSY experiment showed that all these nuclei are close to each other and also to an $\mathrm{sp}^{2}$ carbon-bonded proton resonating at $\delta 5.8(\mathrm{~s}, 1 \mathrm{H})$. Further downfield there are signals at $\delta 2.91(\mathrm{~m}, 1 \mathrm{H}), 3.12(\mathrm{~m}, 1 \mathrm{H}), 3.36(\mathrm{~m}, 1 \mathrm{H})$ and $3.67(\mathrm{dd}$, $1 \mathrm{H}, J=7.0,2.8 \mathrm{~Hz}$ ) also corresponding to neighboring methylene groups as established by the COSY experiment. Another two adjacent methylene groups give rise to signals at $\delta 2.36(\mathrm{~m}, 1 \mathrm{H}), 2.54(\mathrm{~m}, 1 \mathrm{H}), 3.07(\mathrm{~m}, 1 \mathrm{H})$ and 3.26 $(\mathrm{m}, 1 \mathrm{H})$. Three methoxyl singlets appear at $\delta 3.30(\mathrm{~s}, 3 \mathrm{H}), 3.76(\mathrm{~s}, 3 \mathrm{H})$ and $3.78(\mathrm{~s}, 3 \mathrm{H})$, the first one presumably bonded to an $\mathrm{sp}^{3}$ carbon atom. Finally, two protons resonate at $\delta 6.78(\mathrm{~s}, 1 \mathrm{H})$ and $6.80(\mathrm{~s}, 1 \mathrm{H})$ which, in an Erythrina alkaloid, would be expected to reside at the generally free para positions (C-14 and $\mathrm{C}-17$ ) of the aromatic ring.

The ${ }^{13} \mathrm{C}$ NMR spectrum shows the presence of 19 signals, and the APT shows that six of these correspond to quaternary carbons $(\delta$ 149.4, 147.8, $139.3,124.4,123.8$ and 66.99 , the latter with $\mathrm{sp}^{3}$ hybridization and the first two representing oxygen-bonded $\mathrm{sp}^{2}$ carbons), and five to methines $(\delta 125.8,112.4$, $110.8,80.17$ and 71.36 , the first three involving $\mathrm{sp}^{2}$ carbons and the latter two with oxygen-bonded $\mathrm{sp}^{3}$ carbons). Three methoxyl carbons resonate at $\delta 55.44$, 55.51 and $56.45 \mathrm{ppm}$, with the five remaining signals $(\delta 46.74,40.09,37.76$, 25.60 , and 20.85) corresponding to methylene groups.

The HMQC experiment shows connectivities between the protons resonating at $\delta 1.75$ and 2.42 with the $\delta 37.76$ carbon nucleus, confirming that both protons are diasterotopic. According to the ${ }^{1} \mathrm{H}$ NMR spectrum, these protons are coupled to the one at $\delta 3.61$, which in turn is connected to the $\delta$ 80.17 carbon. The latter nucleus is coupled to the $\delta 4.24$ proton, connected to the $\delta 71.36$ carbon which should bear a hydroxyl group and which is also coupled to the $\delta 5.80$ proton, connected to the $\delta 125.8$ carbon. Other diastereotopic methylene proton pairs resonate at $\delta 2.91$ and 3.12, bonded to the $\delta 20.85$ carbon; at $\delta 3.36$ and 3.67 , to the $\delta 40.09$ carbon; $\delta 2.36$ and 2.54 
to the $\delta 25.6$ carbon; and $\delta 3.07$ and 3.26 to the $\delta 46.74$ carbon. The presumed aromatic ring protons resonating at $\delta 6.78$ and 6.80 are attached to the $\delta 112.4$ and 110.8 carbon atoms, respectively. The methoxyl correlations are $\delta 3.30$ to $56.45, \delta 3.76$ to 55.51 , and $\delta 3.78$ to 55.14

Analysis of the HMBC spectrum shows long-range connectivities of the protons resonating at $\delta 1.75$ and $\delta 2.42$ with the $\delta 66.99,71.36,80.17,124.4$ and 138.3 carbons. Similarly, the protons at $\delta 2.91$ and 3.12 are correlated with the $\delta 20.85,40.59,46.74$ and 112.4 carbons; the $\delta 3.36$ and 3.67 protons with the $\delta 37.76,123.8$ and 125.8 carbons; and the $\delta 3.07$ and 3.26 protons with the $\delta 20.85$ and 66.99 carbons. The two protons resonating at $\delta 6.78 / 6.80$ show connectivity with several carbon nuclei: $\delta 20.85,66.99,110.8,112.4,123.8$, 147.8 and 149.7. Nevertheless, the most useful correlations for a complete assignment are those of the well identified methoxyl resonances: the protons at $\delta 3.76$ are correlated with the $\delta 147.4$ and 110.8 carbons, $\delta 3.78$ with the $\delta$ 149.4 and 112.4 carbons, and the $\delta 3.30$ proton with the $\delta 80.17$ carbon. All the correlations are summarized in Table1.

A NOESY experiment was run to establish the relative stereochemistry of $\mathbf{5}$, specifically at $\mathrm{C}-2$ and $\mathrm{C}-3$. As shown by the COSY experiment, $\mathrm{C}-2$ is bonded to a hydroxyl and C-3 to a methoxyl group. The proton resonating at $\delta 6.80$ lies close to the one at $\delta 3.61$, implying that the methoxyl is oriented toward the back of the structure, as shown in Figure 2a. On the other hand, the lone hydroxyl group must face forward as the protons resonating at $\delta 5.80$ and 4.24 lie spatially close to each other, while the one at $\delta 3.61$ does not interact with the former through space. In consequence, the ${ }^{1} \mathrm{H}$ and ${ }^{13} \mathrm{C}$ resonances of epierythratidine (6) have been completely and unambiguously assigned.

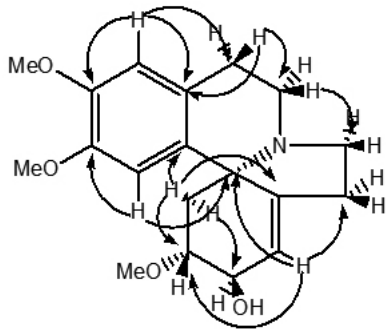

(a)

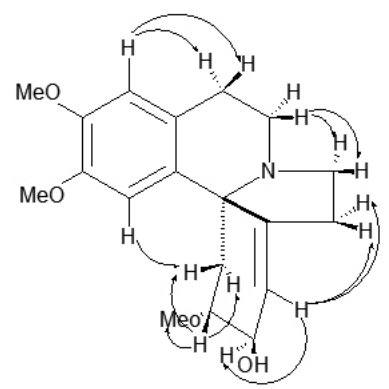

(b)
Figure 2. (a) HMBC correlations and (b) NOESY correlations for epierythratidine (6).

Our data for erysotrine (1), erysodine (2), erythraline (3), erytharbine (4), and erysotrine $\mathrm{N}$-oxide (5), backed up by two-dimensional experiments, lead to assignments that are in complete agreement with those published in the reviews of Chawla et al. ${ }^{1}$ and Amer et al., ${ }^{2}$ and in most of the later papers, which follow a common pattern. The only assignments we have identified diverging from this scheme are in the previously cited article on E. fusca alkaloids by Calle et al. ${ }^{25}$ where the ${ }^{13} \mathrm{C}$ NMR assignments of C-1 (135.5 ppm) and C-2 (123.2 $\mathrm{ppm}$ ) of 8-oxoerysodine, using only one-dimensional spectra, are inverted, and in a paper by Flausino et al., ${ }^{27}$ using ${ }^{1} \mathrm{H}-{ }^{1} \mathrm{H}$ COSY, HMQC and $\mathrm{HMBC}$, who arrived at a similar conclusion for 11a-hydroxyerythravine (in pyridine- $d_{5}$ ) and 11a-hydroxyerysotrine (in $\mathrm{CDCl}_{3}$ ): $\delta 135.0$ and $131.5(\mathrm{C}-1), 124.5$ and 125.5 (C-2), plus 124.4 and 123.5 (C-7), respectively. With the possible exception of the 11a-hydroxyerythravine spectrum, due to the specific solvation of the hydroxyl group by pyridine, these assignments are most likely in error. Any future isolation of these compounds should be accompanied by a thorough study of their NMR spectra in order to clear up these points in doubt.

Recently, Bifulco et al. ${ }^{24}$ developed a new methodology using molecular dynamics (MD) for the search of conformers and QM calculation, which has proved useful to study the conformational change or distortion in polycyclic diasteroisomeric systems. We have used MD using an Amber type force field to search for the differences between the two possible steroisomers of compound 6 (Figure 3). In each case, only a single conformer of the ring system was found. It is worth pointing out that the conformation to the methoxy group in the aromatic ring presents a distribution due to the diehedral torsion. The resulting geometries for both isomers are shown in Figure 4A.

The QM calculation of ${ }^{13} \mathrm{C}$ NMR chemical shifts and proton-proton $J_{\mathrm{H}, \mathrm{H}}$ coupling constants was done at the mPW1PW91/6-31G(d,p) level of theory from the optimized structures for both minima obtained in the MD, with the same functional and the $6-31 \mathrm{G}(\mathrm{d})$ basis set (Figure 4B), because this method minimizes the error in this type of calculation..$^{21}$ The NMR results are summarized in Table 2. The differences between theoretical and experimental values $\Delta \mathrm{d}=\left|\delta_{\text {exp }}-\delta_{\text {calc }}\right|$, which give a measure of the dispersion between the theoretical and experimental chemical shift values for both isomers, and the MAE $=\sum\left[\left|\delta_{\text {Exp }}-\delta_{\text {Calc }}\right|\right] / n$ parameter, that represents the measure of absolute error, have proved very useful for the characterization of stereostructures. ${ }^{17}$

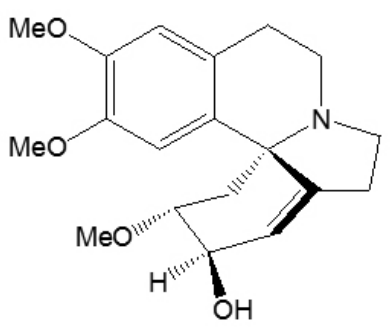

$6 a$<smiles>COc1cc2c(cc1OC)[C@]13CCN1CCC2=C[C@@H]([C@@H](O)[C@H](C)CO)C3</smiles>

6b
Figure 3. Two alternative structures for epierythratidine $\mathbf{6 a}$ and $\mathbf{6 b}$
A

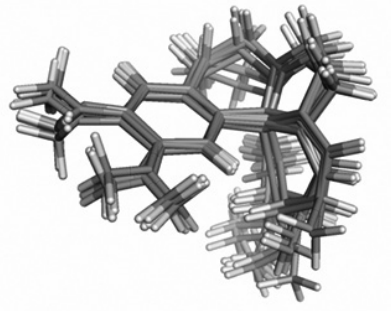

B

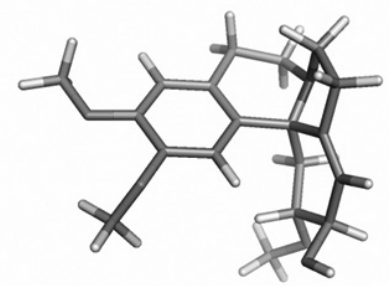

$6 a$
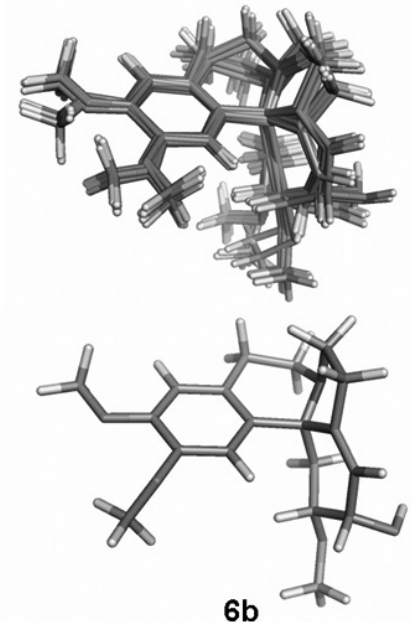

$6 b$
Figure 4. (A) Molecular Dynamics search of conformers (B) optimized geometries for both isomers $\mathbf{6 a}$ and $\mathbf{6 b}$.

These values show that $|\Delta \delta|$ for $\mathrm{C}-2$ and $\mathrm{C}-3$ are 0.4 and 0.9 , respectively, for structure $\mathbf{6 a}$, much smaller than the increments in these values for structure 6b (7.2 and 7.3, respectively), indicating that the match with the experimental data for both carbons strongly supports structure 6a. This result is fundamental for the structure reassignment for compound $\mathbf{6}$, considering that the other carbon nuclei present similar $|\Delta \delta|$ values. On the other hand, the differences between the averages of the MAE values for $\mathbf{6 a}$ and $\mathbf{6} \mathbf{b}$ are 3.7 and 5.0, respectively. It should be pointed out that the increment in the MEA is due to the aromatic ring, this is a problem in these measurements since the limit for the error in the method for calculation ${ }^{13} \mathrm{C}$ chemical shift exceeds $100 \mathrm{ppm} .{ }^{28}$ However, the values for the non-aromatic rings are in agreement with those obtained from the experimental results.

In summary, the differences reported in the literature for the ${ }^{13} \mathrm{C}$ chemical shift show greater dispersion and inversions in $\mathrm{C} 2$ and $\mathrm{C} 3$ for both isomers studied. Our results can be judged to be in good agreement with the experimental data for the structural reassignment of compound 6 . On the other hand, due to the fact that the signals for $\mathrm{H}-1, \mathrm{H}-2, \mathrm{H}-7, \mathrm{H}-8, \mathrm{H}-10$ and $\mathrm{H}-11$ are multiplets, the coupling constants cannot be easily obtained from the experimental data. However, the coupling constants for protons $\mathrm{H}-3$ and $\mathrm{H}-4$ have been correlated with the calculations which reinforce the comparison with the experimental results.

\section{CONCLUSION}

From the seeds of Erythrina fusca Lour. were isolated and identified by spectroscopic methods the alkaloids erysotrine (1), erysodine (2), erythraline 
(3), erytharbine (4), erysotrine $N$-oxide (5) and epierythratidine (6). The structure of compound $\mathbf{6}$ was reassigned based on experimental and theoretical NMR studies. Our results show that a MD conformational search followed by GIAO/DFT QM calculations on the energy-minimized structures provide an excellent agreement with the experimental ${ }^{13} \mathrm{C}$ chemical shifts and a fair agreement with the experimental ${ }^{3} J_{\mathrm{H}, \mathrm{H}}$ coupling constants. These values confirm and support the experimentally derived assignments and structure of epierythratidine (6).

Table 2. Comparison of calculated vs. experimental ${ }^{13} \mathrm{C}$ NMR chemical shifts and theoretical ${ }^{3} J_{\mathrm{H}, \mathrm{H}}$ coupling constant values for compounds $6 \mathbf{a}$ and $\mathbf{6 b}$.

\begin{tabular}{|c|c|c|c|c|c|c|c|c|}
\hline \multirow[b]{2}{*}{ C No. } & \multirow[t]{2}{*}{$\mathrm{d}^{13} \mathrm{C}_{\text {Exp }}$} & \multicolumn{2}{|c|}{$\mathrm{d}{ }^{13} \mathrm{C}_{\text {Calc }}$} & \multicolumn{2}{|c|}{ |Dd|,ppm* } & \multicolumn{3}{|c|}{${ }^{3} J_{\mathrm{H}, \mathrm{H}}(\mathrm{Hz})$} \\
\hline & & $6 a$ & $6 \mathrm{~b}$ & $6 a$ & $6 b$ & & $6 a$ & $6 b$ \\
\hline 1 & 125.3 & 120.8 & 121.0 & 4.5 & 4.3 & $J_{\mathrm{H} 1 \mathrm{H} 2}$ & 4.75 & 4.60 \\
\hline 2 & 71.36 & 71.73 & 64.12 & $\underline{0.4}$ & 7.2 & $J_{\mathrm{H} 2, \mathrm{H} 3}$ & 4.69 & 5.77 \\
\hline 3 & 80.17 & 79.28 & 72.84 & $\underline{0.9}$ & $\underline{7.3}$ & $\begin{array}{l}J_{\mathrm{H} 3, \mathrm{H} 4 \mathrm{a}} \\
J_{\mathrm{H} 3, \mathrm{H} 4 \mathrm{~b}}\end{array}$ & $\begin{array}{c}10.99 \\
4.75 \\
\end{array}$ & $\begin{array}{r}11.33 \\
4.17 \\
\end{array}$ \\
\hline 4 & 37.76 & 39.40 & 40.33 & 1.6 & 2.6 & & & \\
\hline 5 & 66.99 & 65.83 & 65.35 & 1.2 & 1.6 & & & \\
\hline 6 & 139.3 & 145.1 & 145.0 & 5.8 & 5.8 & & & \\
\hline 7 & 25.60 & 29.14 & 29.58 & 3.5 & 4.0 & $\begin{array}{l}J_{\mathrm{H} 7 \mathrm{a}, \mathrm{H} 8 \mathrm{a}} \\
J_{\mathrm{H} 7 \mathrm{~b}, \mathrm{H} 8 \mathrm{~b}} \\
J_{\mathrm{H} 7 \mathrm{a}, \mathrm{H} 8 \mathrm{~b}}\end{array}$ & $\begin{array}{l}9.46 \\
9.05 \\
1.33 \\
\end{array}$ & $\begin{array}{l}9.76 \\
9.05 \\
1.15 \\
\end{array}$ \\
\hline 8 & 46.74 & 46.57 & 45.95 & 0.2 & 0.8 & & & \\
\hline 10 & 40.09 & 40.48 & 40.88 & 0.4 & 0.8 & $\begin{array}{l}J_{\mathrm{H} 10 \mathrm{a}, \mathrm{H} 11 \mathrm{a}} \\
J_{\mathrm{H} 10 \mathrm{~b}, \mathrm{H} 11 \mathrm{~b}} \\
J_{\mathrm{H} 10 \mathrm{~b}, \mathrm{H} 11 \mathrm{a}}\end{array}$ & $\begin{array}{c}7.22 \\
6.00 \\
10.71 \\
\end{array}$ & $\begin{array}{c}7.37 \\
6.23 \\
10.60 \\
\end{array}$ \\
\hline 11 & 20.85 & 23.32 & 23.29 & 2.5 & 2.4 & & & \\
\hline 12 & 123.8 & 127.2 & 127.3 & 3.4 & 3.5 & & & \\
\hline 13 & 124.4 & 125.4 & 125.2 & 1.1 & 0.9 & & & \\
\hline 14 & 110.8 & 118.8 & 119.2 & 8.0 & 8.4 & & & \\
\hline 15 & 147.4 & 141.6 & 141.3 & 5.7 & 6.1 & & & \\
\hline 16 & 149.4 & 147.2 & 147.3 & 2.1 & 2.1 & & & \\
\hline 17 & 112.4 & 109.9 & 109.5 & 2.4 & 2.9 & & & \\
\hline $1^{\prime}$ & 56.45 & 57.67 & 57.17 & 1.2 & 0.7 & & & \\
\hline $2^{\prime}$ & 55.51 & 55.32 & 54.46 & 0.2 & 1.0 & & & \\
\hline $3^{\prime}$ & 55.14 & 52.59 & 52.59 & 2.5 & 2.6 & & & \\
\hline MAE* & & & & 3.7 & 5.0 & & & \\
\hline
\end{tabular}

$*|\Delta \mathrm{d}|=\left|\delta_{\exp }-\delta_{\text {calc }}\right|$ and MAE $=\sum\left[\left|\delta_{\text {Exp }}-\delta_{\text {Calc }}\right|\right] / \mathrm{n}$

\section{MATERIAL AND METHODS}

\subsection{Plant material}

Erythrina fusca Lour. seeds were collected on the campus of Tolima University, Ibagué, central Colombia, $4^{\circ} 25^{\prime} \mathrm{N}, 75^{\circ} 12^{\prime} \mathrm{W}, 1,100 \mathrm{~m}$ above sea level, by Olimpo García in February 2007. The plant material was identified by Prof. Tirso Medina, and a voucher specimen was deposited in the Herbarium of the Biology Department of Tolima University.

\subsection{Extraction and isolation}

Dried, ground seeds $(3,200 \mathrm{~g})$ of $E$. fusca were defatted with petroleum ether and then exhaustively extracted with methanol at room temperature over a period of 7 days. After concentration under reduced pressure, a viscous yellow liquid $(45.5 \mathrm{~g})$ was obtained and taken up with $3 \% \mathrm{HCl}$. The acid solution was extracted several times with $\mathrm{CHCl}_{3}$ and was then made alkaline (pH 9-10) with concentrated aqueous $\mathrm{NH}_{3}$ and re-extracted with $\mathrm{CHCl}_{3}$ to afford the crude alkaloids $(6.8 \mathrm{~g})$. The alkaloid fraction was subjected to silica gel column chromatography eluting with $\mathrm{CH}_{2} \mathrm{Cl}_{2}-\mathrm{CH}_{3} \mathrm{OH}$ (95:5 to 80:20), to yield fortythree $200 \mathrm{~mL}$ fractions which were pooled according to their TLC patterns, and fractionated again by preparative TLC to afford the pure alkaloids. In this way erysotrine (1,24 mg), erysodine (2, 45 mg), erythraline (3, $68 \mathrm{mg})$, erytharbine $(\mathbf{4}, 82 \mathrm{mg})$, and erysotrine $N$-oxide $(\mathbf{5}, 20 \mathrm{mg})$ were obtained. One of the later fractions deposited crystals upon concentration. These were washed with cold acetone and recrystallized in $\mathrm{MeOH}$ to provide epierythratidine $(6,450 \mathrm{mg})$.

\subsection{NMR studies}

Compounds $1,2,3,4$, and 5 were dissolved in $\mathrm{CDCl}_{3}$, and $\mathbf{6}$ in $\mathrm{CD}_{3} \mathrm{OD}$ for spectroscopic analysis using a Bruker multidimensional spectrometer $(400$ $\mathrm{MHz}$ for ${ }^{1} \mathrm{H}$ and $100 \mathrm{MHz}$ for ${ }^{13} \mathrm{C}$ ) and a Bruker DRX300 spectrometer (300 $\mathrm{MHz}$ for ${ }^{1} \mathrm{H}$ and $75 \mathrm{MHz}$ for ${ }^{13} \mathrm{C}$ ), respectively. TMS was used as an internal standard and the temperature was kept at $298 \mathrm{~K}$ for all experiments. Twodimensional experiments were performed using standard Bruker software for ${ }^{1} \mathrm{H}--^{1} \mathrm{H}$ COSY (cosygpqf and cosygs), NOESY (noesygpph), HMQC (inv4gpqf and inv4gstp) and HMBC (inv4gplrndqf and inv4gslplrnd).

\subsection{Computational details}

The conformer search by Molecular Dynamics was performed after minimization of the energy using an Amber model for parameters and force field, with a standard constant temperature velocity-Verlet algorithm. All the structures obtained from MD calculations for each isomer were minimized using the Polak-Ribier conjugate gradient algorithm (PRCG, 100 steps, convergence threshold $0.005 \mathrm{~kJ} \mathrm{~mol}^{-1} \AA^{-1}$ ), implemented in the Gabaedit 2.6 program, ${ }^{29}$ leading to the selection of the lowest energy minimum conformer for each diastereoisomer, which were optimized at the mPW1PW91/6-31G(d) level of theory. The ${ }^{13} \mathrm{C}$ NMR chemical shifts and coupling constants were calculated using the GIAO (Gauge Invariant Atomic Orbitals) method, ${ }^{30}$ together with solvent effects which were evaluated by performing single-point mPW1PW91/6-31G(d,p) calculations at the gas-phase stationary points using Tomasi's group's polarizable continuum model (PCM). ${ }^{31,32}$ The dielectric 
constant was set at $\varepsilon=32.63$ for methanol. Relative chemical shifts were estimated by using the corresponding TMS shielding calculated at the same level of theory and using the PCM method to model the solvent effect. All QM calculations were carried out with the Gaussian 03 suite of programs. ${ }^{33}$

\section{ACKNOWLEDGEMENTS}

The authors are pleased to acknowledge financial support from the Millennium Scientific Initiative (Grant P05-001-F). JSD acknowledges a PostDoctoral Fellowship from a Millennium Nucleus (CILIS), ICM-P10-003-F.

\section{REFERENCES}

1.- A. Chawla, S. Chunchatprasert, A. Jackson. Org. Magn. Reson. 21, 39 (1984).

2.- $\quad$ M. Amer, M. Shamma, A. Freyer, J. Nat. Prod. 54, 329 (1991).

3.- H. Tanaka, T. Tanaka, H. Etoh, Phytochemistry 48, 1461 (1998).

4.- D.L. Yu, J. Guo, L.Z. Xu, S.L. Yang, Chin. Chem. Lett. 10, 139 (1999).

5.- C.C.W. Wanjala, R.R.T. Majinda, J. Nat. Prod. 63, 871 (2000).

6.- $\quad$ B.F. Juma, R.R.T. Majinda, Phytochemistry 65, 1397 (2004).

7.- $\quad$ A. Freyer, J. Huffman, M. Menachery, K. Huey, W. Leavens, R. Fitch, J. Nat. Prod. 69, 1514 (2006).

8.- H. Tanaka, H. Hattori, T. Tanaka, E. Sakai, N. Tanaka, A. Kulkarni, H. Etoh, J. Nat. Med. 62, 228 (2008).

9.- T. Rukachaisirikul, P. Innok, A. Suksamrarn, J. Nat. Prod. 71, 156 (2008).

10.- J. Casanovas, A.M. Namba, C.R da Silva, C. Alemán, Bioorg. Chem. 33, 484 (2005).

11.- G. Bifulco, L. Gómez-Paloma, R. Riccio, Tetrahedron Lett. 44, 7137 (2003).

12.- G.V.J. da Silva, A. Cunha-Neto, Tetrahedron 61, 7763 (2005).

13.- M.G. Chini, R. Riccio, G. Bifulco, Magn. Reson. Chem. 46, 962 (2008).

14.- P. Tähtinen, G. Saielli, G. Guella, I. Mancini, A. Bagno, Chem. Eur. J. 14, 10445 (2008)

15.- C. Areche, A. San-Martín, J. Rovirosa, J. Soto-Delgado, R. Contreras, Phytochemistry 70, 1315 (2009).

16.- S. Di Micco, M.G. Chini, R. Riccio, G. Bifulco, Eur. J. Org. Chem. 8, 1411 (2010).

17.- G. Bifulco, P. Dambruoso, L. Gómez-Paloma, R. Riccio, Chem. Rev. 107, 3744 (2007).
18.- P. Cimino, G. Bifulco, A. Evidente, M. Abouzeid, R. Riccio, L. GómezPaloma, Org. Lett. 4, 2779 (2002).

19.- D.C. Braddock, H.S. Rzepa, J. Nat. Prod. 71, 728 (2008).

20.- A. Plaza, S. Piacente, A. Perrone, A. Hamed, C. Pizza, G. Bifulco, Tetrahedron 60, 12201 (2004).

21.- P. Cimino, D. Duca, L. Gómez-Paloma, R. Riccio, G. Bifulco, Magn. Reson. Chem. 42, S26 (2004).

22.- C. Bassarello, A. Zampella, M.C. Monti, L. Gómez-Paloma, M.V. Dauria, R. Riccio, G. Bifulco, Eur. J. Org. Chem. 3, 604 (2006).

23.- A. San Martín, J. Rovirosa, A. Carrasco, S. Orejarena, J. Soto-Delgado, R. Contreras, M.C. Chamy, Nat. Prod. Commun. 5, 1859 (2010).

24.- M.G. Chini, C.R. Jones, A. Zampella, M.V. Da'Auria, B. Renga, S. Fiorucci, C.P. Butts, G. Bifulco, J. Org. Chem. 77, 1489 (2012).

25.- J. Calle, R. Pinzón, L.F. Ospina, N.C. Medina, A. Carrión, Rev. Col. Cienc. Quim. Farm. 26, 39 (1997).

26.- M. Soto-Hernández, A.H. Jackson, Planta Med. 60, 175 (1994).

27.- O. Flausino, L. de Avila Santos, H. Verli, A.M. Pereira, V. da Silva Bolzani, R.L. Nunes de Souza, J. Nat. Prod. 70, 48 (2007).

28.- S.D. Rychnovsky, Org. Lett. 8, 2895 (2006).

29.- A.R. Allouche, Gabedit - A graphical user interface for computational chemistry softwares, J. Comput. Chem. 32, 174 (2010).

30.- K. Wolinski, J.F. Hilton, P. Pulay, J. Am. Chem. Soc. 112, 8251 (1990).

31.- V. Barone, M. Cossi, J. Tomasi, J. Comput. Chem. 19, 404 (1998).

32.- J. Tomasi, M. Persico, Chem. Rev. 94, 2027 (1992).

33.- M.J. Frisch, G.W. Trucks, H.B. Schlegel, G.E. Scuseria, M.A. Robb, J.R. Cheeseman, J.A. Montgomery, T. Vreven, K.N. Kudin, J.C. Burant, J.M. Millam, S.S. Iyengar, J. Tomasi, V. Barone, B. Mennucci, M. Cossi, G. Scalmani, N. Rega, G.A. Petersson, H. Nakatsuji, M. Hada, M. Ehara, K. Toyota, R. Fukuda, J. Hasegawa, M. Ishida, T. Nakajima, Y. Honda, O. Kitao, H. Nakai, M. Klene, X. Li, J.E. Knox, H.P. Hratchian, J.B. Cross, V. Bakken, C. Adamo, J. Jaramillo, R. Gomperts, R.E. Stratmann, O. Yazyev, A.J. Austin, R. Cammi, C. Pomelli, J.W. Ochterski, P.Y. Ayala, K. Morokuma, G.A. Voth, P. Salvador, J.J. Dannenberg, V. G. Zakrzewski, S. Dapprich, A.D. Daniels, M.C. Strain, O. Farkas, D.K. Malick, A. D. Rabuck, K. Raghavachari, J.B. Foresman, J.V. Ortiz, Q. Cui, A.G. Baboul, S. Clifford, J. Cioslowski, B.B. Stefanov, G. Liu, A. Liashenko, P. Piskorz, I. Komaromi, R.L. Martin, D.J. Fox, T. Keith, M.A. Al-Laham, C.Y. Peng, A. Nanayakkara, M. Challacombe, P.M.W. Gill, B. Johnson, W. Chen, M.W. Wong, C. Gonzalez, J.A. Pople, Gaussian 03, Revision C.02, Gaussian, Inc.: Wallingford CT. 2004. 